\title{
Discussion on the Way out of Rural "Care Rotation" of the Elderly Under the Background of Modern Vocational Education System
}

\begin{abstract}
Yaohui $\mathrm{Xu}^{1}$
${ }^{1}$ School of Political Science And Law University Of Jinan

*Email:857560298@qq.com

ABSTRACT

With the development of urbanization and cultural changes, "care rotation" has become the main mode of caring for the elderly in rural areas. However, at the micro level, the current "care rotation" model in rural areas reflects the problems of the rotation conflict between children, the fairness of male and female support, and the low efficiency of family care for the elderly. At the social level, it not only reflects the lack of pension service and management talents, but also reflects the imperfection of vocational education for elderly care in China. Therefore, under the background that China is accelerating the construction of modern vocational education system and vigorously cultivating skilled talents, families, communities and institutions should make full use of the favorable policies of vocational education for elderly, so as to have an effect on the arrival of population aging.
\end{abstract}

Keywords: Vocational Education for elderly care, "Care rotation" of the elderly, Equity in maintenance

\section{RESEARCH BACKGROUND AND LITERATURE REVIEW}

Influenced by traditional Confucian ideology and self-supporting mode of production, the responsibility of supporting the elderly is mostly undertaken by the family. With the change of family structure and production mode, taking turns to take care of the elderly among children has become a common way of supporting the elderly in rural areas.

Domestic research on the "care rotation" of the elderly in rural areas shows certain regional characteristics. Most of these researches focus on the field investigation in Hebei area ${ }^{[1]}$, and summarize the reasons for choosing "rotation" and the conflicts in the process of "rotation" through qualitative research ${ }^{[2]}$. As for the theoretical explanation of conflict, the academic circles usually start from the change of family rights ${ }^{[3]}$, or the fairness of intergenerational exchange ${ }^{[4]}$. Tian Peng (2019) divided four types of pension practice according to the two dimensions of "residential structure intergenerational relationship", and pointed out that the common rotation type is the ideal choice for Chinese traditional families ${ }^{[5]}$. The research on family support in foreign countries has more awareness of rights. Ben Porath (1980) thinks that the relationship between parents and children is more like a contractual relationship. The material interaction between parents and children comes from the flow and exchange between material and non-material ${ }^{[6]}$, which is similar to the view of Chinese scholar Zhang Jun (2018) ${ }^{[2]}$.

\section{THE FORMATION OF "CARE ROTATION" MODE}

"Care rotation" has been formed in Chunqiu period, but with the changes of the times, "rotation" also has corresponding changes, the reasons for this change usually include two aspects.

\subsection{The Discretization of Parents and Children's Residence}

With the convenience of transportation and the development of urbanization, the phenomenon of traditional big families living together is gradually declining, and the living between parents and children is characterized by discretization. 


\subsubsection{Separation Between Rural and Urban Areas}

Under the background of urbanization, a large number of young and middle-aged workers in rural areas flow into cities, obtain stable jobs in cities, and then transform into urban permanent residents. As a result, the phenomenon of parents and children living in rural and urban areas is increasing.

\subsubsection{Separation of Township (town)}

Moving from a rural area to another rural or township area usually involves two things. One is the migration of residence due to marital relationship, which is also the main reason; Second, due to the development of township enterprises caused by the inter-village flow, thus, the parent-child separation in the township-township (town) phenomenon is more common.

\subsection{The Elderly are Weak in their Ability to Provide for the Aged}

In terms of physical function, with the growth of age, the physical function of the elderly will decline, the number of chronic diseases will increase, and even eventually lead to the inability to take care of themselves. The data show that $18 \%$ of the elderly will need daily life care due to physical reasons ${ }^{[7]}$; In terms of material data, the main source of living for the elderly will disappear after they leave the labor field, while social security can provide very little material help. Especially after the "separation" of their children, the ownership and control of land and housing of the elderly will be transferred to other people, from which the elderly can not obtain the source of living; From the psychological level, with the aggravation of rural hollowing, there are fewer and fewer people who can accompany the elderly, and the spiritual world of the elderly is becoming more and more empty, which is not conducive to their physical and mental health.

With the development of society, the space distance between the parents and children is increasing gradually. Most of the elderly in rural areas can only rely on their families. In a family with many children, if the elderly only rely on the care of their children, it will inevitably lead to injustice to the latter, and the cost of care for the elderly is difficult to be measured by money. Therefore, under the balance of money, time and obligation, the families with children will eventually choose a floating family style pension model in which multiple families take turns to take care of the elderly. The final result of this model can not only enable the offspring families to have a certain amount of time each year to ensure the reproduction function of their own families, but also maintain the integration state of traditional families ${ }^{[2]}$.

\section{PROBLEMS IN THE MODE OF "CARE ROTATION" IN RURAL AREAS}

The content of the maintenance obligation mainly includes: material economy, spiritual comfort and life care. In today's society, material economy is no longer a problem that plagues most families. The maintenance of the elderly is mostly focused on spiritual comfort and life care.

\subsection{Lack of Spiritual Comfort}

After the old people withdraw from the labor field, the change of their role will cause the old people's psychological discomfort, resulting in the decline of self-identity and many other negative emotions. In this case, it is particularly important to pay attention to the spiritual world and mental health of the old people. Participation in social activities has a significant impact on the well-being and life satisfaction of the elderly. However, through the quantitative analysis of CHARLS data, many scholars found that most of the rural areas lack of attention to cultural construction, and it is difficult for the rural elderly to obtain the cultural and recreational activities supported by the community and the government, such as the elderly activity center, the elderly training class, and becoming elderly volunteers, just like the urban elderly ${ }^{[7]}$.

\subsection{The Conflict of Rotation Fairness among Multiple Caregivers}

In the traditional society, people pay more attention to the kinship and geographical relationship, but with the change of society, mechanical unity changes to organic unity, people become more care rational in their daily life, and more attention turns to interests and fairness, so the traditional concept of providing for the aged is impacted. When the logic of fairness can not be recognized, it will lead to conflict.

\subsubsection{Unequal Rights and Obligations Between Men and Women}

Although the law clearly stipulates that "men and women are equal in inheritance", in some rural areas, all property is still inherited by male heirs, and it is not uncommon for women to voluntarily or forcibly give up the right of inheritance. This leads to the problem of rural women's support for their parents. Women who voluntarily give up the right to inherit property refuse to support the elderly. Women who are forced to give up the right to inherit property may also refuse or be unable to support the elderly because of the loss of "sense of fairness". 


\subsubsection{Intergenerational Exchange Inequality Between Father and Son}

Some scholars have found that the conflicts caused by intergenerational exchange inequality are usually manifested in two aspects: first, before the children fulfill their maintenance obligations, they will have expectations of the economic, material and resources owned by their parents. Once the children do not get these resources, they may refuse to support them; second, they may refuse to support their parents; Second, there is a strong demand for fairness. If a child gets more material and resources from his father because of his father's love or other reasons, it will cause other children's "sense of unfairness". As a result, other children may unanimously ask the party with more resources to fulfill more obligations ${ }^{[4]}$.

\subsection{The Sense of Belonging of the "Care Rotation" Elderly Decreased}

In modern society, it is an indisputable fact that the concept of family and the sense of kinship are weakening. In this case, the elderly suddenly enter into the children's family for life, which may disturb the original life rules or family atmosphere in the family. For some children's families, the elderly are more like "outsiders". Due to psychological reasons, the elderly usually form a certain dependence on the long-term living environment. After leaving the original environment, they can feel the loneliness caused by no belonging. Moreover, the old people's ability to accept new things is low, and their original living habits may conflict with their children's families, which easily leads to conflicts between parents and children. It further reduces the sense of belonging and satisfaction of the elderly to the "new home", and the quality of life of the elderly can not be guaranteed.

\subsection{The Efficiency of Family Care for the Elderly is Low}

The data show that when families provide elderly care, their children's working hours will be significantly reduced ${ }^{[8]}$. Especially for women, elderly care will not only reduce their weekly working hours, but also significantly reduce their income, which will reduce their children's original quality of life ${ }^{[9]}$. At the same time, the family is usually unable to provide professional care for the elderly, especially for some sick and unable to take care of themselves. The care that the family can provide is usually unable to meet the needs of the elderly, and the final result is to reduce the quality of life of the elderly.

\section{ANALYSIS ON THE VOCATIONAL EDUCATION FOR ELDERLY CARE IN THE "CARE ROTATION" MODEL}

With the change of society, the rural family pension problem is no longer a problem within a single family, it has risen to the social level. Social problems, such as the decline of family pension function, the core of family structure, the increase of elderly dependency ratio and rural hollowing out, are encouraging the government and all sectors of society to pay attention to it. In order to ensure that the elderly in rural areas can live happily in their old age, it is necessary to recognize the responsibility of the government to share the cost of family care. In rural areas, it is still necessary to establish an "elderly care service system based on family care, community support and institution supplement". The author puts forward relevant suggestions from three aspects of the system. At the institutional level, it will mainly emphasize the necessity of pension vocational education.

\subsection{Family Fundamentals}

For a long time, system support and cultural influence have ensured the basic status of family support for the aged in China, which cannot be shaken.

\subsubsection{Financial Subsidies for Family Caregivers}

In the family, from the perspective of Marx's commodity economy theory, the social value and economic value created by the elderly family caregivers are very considerable; Compared with social pension, family pension, as the most important pension mode in today's society, reduces the government's financial investment to the greatest extent. More scholars calculate that the value of unpaid family care is 13 to 22 times of the government's pension fund ${ }^{[10]}$. Therefore, the government should provide financial subsidies to the elderly family caregivers according to a certain proportion, which may increase the enthusiasm of the children to take care of the elderly in turn.

\subsubsection{Advocating Equality Between Men and Women and Modern Filial Piety Culture}

The lack of rural women's property inheritance right is an important factor for women to withdraw from the field of supporting the elderly. But practice has proved that "daughter pension" has its unique advantages, even more popular in some areas. Whether from the social moral level or the quality of life of the elderly, women should not withdraw from the field of elderly support. This requires the village committee to actively promote the concept of equality. 


\subsection{Community Support Level}

The best mode of rural community endowment service in China should be the combination of home-based endowment and community endowment ${ }^{[11]}$. Therefore, combined with the actual situation of our country, we can carry out the mode of mutual support for the aged in rural areas. Under the leadership of the village committee and other village organizations, we need to integrate the idle resources of the community and establish the activity center for the aged; At the same time, the village committee should also collect information about the need to care for the elderly in the village, and carry out mutual assistance with the people in need of help in the village.

\subsection{Institutional Supplement}

Firstly, due to the small number, high threshold and huge amount of beds in elderly care institutions currently provided to the rural elderly, many rural families are out of reach. This phenomenon runs counter to the responsibility of alleviating the burden of family elderly care. At the same time, relevant departments should also ban some non-compliant nursing homes in rural areas. Secondly, strengthen the professional training of elderly care service personnel, so as to meet the diversity of the needs of the elderly. In order to solve the problem of talent shortage in the elderly service industry, the key is to strengthen the vocational education of the elderly care specialty. Since the promulgation of the decision on accelerating the development of modern vocational education in 2014, China has shown the importance of building a modern vocational education system. At the same time, the state also proposed to cultivate talents under the new business model, including the elderly care service industry. Whether from the perspective of policy support or economic value, cultivating industry applicable talents from the framework of vocational education is of great significance to the progress of society.

\section{CONCLUSION AND PROSPECT}

In general, the improvement of pension needs the cooperation of family, society and government, and should take into account the material economy, spiritual comfort and life care of the elderly at the same time. In addition, under the background of accelerating the development of modern vocational education system in China, we should vigorously cultivate relevant talents and reduce the pressure of social pension. The problem of providing for the elderly is one of the major issues in modern society. Solving the problem of providing for the elderly in rural families is not only an important factor to promote rural economic and cultural construction, but also one of the foundations to ensure the benign operation of society. Only when such problems are solved, can China lay a solid practical foundation for the more severe aging era in the future.

\section{REFERENCES}

[1] Wu Haixia. Rotation analysis of the contemporary rural elderly population -- Based on the experience of Hebei Province [J]. Population research, 2009, 33 (04): 68-77

[2] Zhang Jun. the causes of the conflict in the rotation of the rural elderly: Based on the field survey in Hebei Province [J]. Chongqing Social Sciences, 2018 (03): 33-39

[3] Hu Mingyu. Maintenance agreement system: an analysis of a new rural pension model [J]. Administration and law, 2013 (04): 122-125

[4] Guo Yuhua. The logic of fairness in intergenerational relations and its changes: an analysis of the time of providing for the aged in rural Hebei $[\mathrm{J}]$. Chinese Academy of Sciences, 2001 (4): 221-254

[5] Tian Peng. Practical logic of rural home-based care model transformation in the process of new urbanization [J].JOURNAL OF YUNNAN UNIVERSITY FOR NATIONALITIES (PHILOSOPHY AND SOCIAL SCIENCES EDITION), 2019,36 (02): 96-103

[6] Ben-Porath Y. The F-Connection: Families, Friends, and Firms and the Organization of Exchange[J]. Population \& Development Review, 1980, 6(1): $1-30$.

[7] Zhang Na, Su Qun. Analysis of China's elderly care from the perspective of needs -- Also on the construction of social care system [J]. Academic forum, 2014,37 (06): 135-139

[8] Xiong Jiangyao, Zhang Anan, Yang Jirui. The effect of elderly care on the labor supply of married children: empirical evidence based on CFPS [J]. Financial science, 2020 (04): 121-132

[9] Chen Lu, fan Hongli, Zhao Na, Chu Lanlan. The influence of family care for the elderly on female employment [J]. Economic research, 2016, 51 (03): 176-189

[10] Dai Weidong. Functional change and value turn of family care for the elderly in China [J]. Journal of Anhui Normal University (HUMANITIES AND SOCIAL SCIENCES EDITION), 2021,49 (01): 64-73

[11] Meng Shasha, sun Yiping. Effective supply mode and path of rural elderly care service -- Based on 
the perspective of rural supply side structural reform [J]. Agricultural economy, 2019 (09): 84-85

[12] Cheng Jing, Yuan Guo. Research on talent training of elderly care service specialty in Higher Vocational Colleges under the background of aging [J]. Educational theory and practice, 2019,39 (15): 27-29 